\title{
Sensitivity analysis by the adjoint chemistry transport model DRAIS for an episode in the Berlin Ozone (BERLIOZ) experiment
}

\author{
K. Nester and H.-J. Panitz \\ Institut für Meteorologie und Klimaforschung (IMK), Forschungszentrum Karlsruhe/Universität Karlsruhe, \\ Hermann-von-Helmholtz-Platz 1, 76344 Eggenstein-Leopoldshafen, Germany
}

Received: 2 May 2005 - Published in Atmos. Chem. Phys. Discuss.: 13 September 2005

Revised: 16 January 2006 - Accepted: 19 April 2006 - Published: 20 June 2006

\begin{abstract}
The Berlin Ozone Experiment (BERLIOZ) was carried out in summer 1998. One of its purposes was the evaluation of Chemistry Transport Models (CTM). CTM KAMM/DRAIS was one of the models considered. The data of 20 July were selected for evaluation. On that day, a pronounced ozone plume developed downwind of the city. Evaluation showed that the KAMM/DRAIS model is able to reproduce the meteorological and ozone data observed, except at farther distances $(60-80 \mathrm{~km})$ downwind of the city. In that region, the DRAIS model underestimates the measured ozone concentrations by $10-15 \mathrm{ppb}$, approximately.

Therefore, this study was conducted to detect possible reasons for this deviation. A comprehensive sensitivity analysis was carried out to determine the most relevant model parameters. The adjoint DRAIS model was developed for this purpose, because for this study the application of this model is the most effective method of calculating the sensitivities. The least squares of the measured and simulated ozone concentrations between 08:00 UTC and 16:00 UTC at two stations $30 \mathrm{~km}$ and $70 \mathrm{~km}$ downwind of the city centre were chosen as distance function. The model parameters considered in this study are the complete set of initial and boundary species concentrations, emissions, and reaction rates, respectively. A sensitivity ranking showing the relevance of the individual parameters in the set is determined for each parameter set.
\end{abstract}

In order to find out which modification in the parameter sets most reduces the cost function, simplified 4-D data assimilation was carried out. The result of this data assimilation shows that modifications of the reaction rates provide the best agreement between the measured and the simulated ozone concentrations at both stations. However, the modified reaction rates seem to be unrealistic for the whole simulation period. Therefore, the good agreement should not be overes-

Correspondence to: H.-J. Panitz

(panitz@imk.fzk.de) timated. The agreement is still acceptable when the parameters in the other sets are modified together. The investigation demonstrates that an analysis of this type can help to explain inconsistencies between observations and simulations. But in the case considered here the inconsistencies cannot be explained by an error in only one parameter set.

\section{Introduction}

The Berlin Ozone (BERLIOZ) Experiment (Becker et al., 1999) was carried out in the period between 13 July and 9 August 1998, as part of the German Tropospheric Research Programme (TSF). The experimental domain comprised the city of Berlin and an area within a radius of about $100 \mathrm{~km}$ around the city. The experiment mainly served to study the transport and chemical transformation processes in the urban plume of Berlin under photo-smog conditions. The study focused on the production of ozone and other oxidants. However, the data were also used for evaluating Chemistry Transport Models (CTM). As the chemical production of oxidants, especially ozone, depends on a large number of parameters, many experiments have been carried out to analyze the relevance of the processes involved. Urban plumes are of special interest because of their limited extension and the possibility to relate the plume to the emissions from the city. Unlike other experimental sites in Europe located in complex terrain, e.g. Athens (Peleg et al., 1997), Madrid (Plaza et al., 1997), Milan (Prevot et al., 1997), and Vienna (Wotava et al., 1998), Berlin was selected because of its location in a flat environment extending approximately $100 \mathrm{~km}$ around the city. The urban plume is not influenced by any other major sources in many directions.

In an earlier study, a simulation using the KAMM/DRAIS model was conducted for 20 July (Nester et al., 2000). Its results were compared with measured meteorological and chemical data. As in the investigation by Memmesheimer

Published by Copernicus GmbH on behalf of the European Geosciences Union. 
et al. (1997), additional mass budget calculations were performed (Panitz and Nester, 2002) to determine the relevant processes as function of time and space. Those evaluations showed the KAMM/DRAIS model to be able to reproduce the observed data, except the ozone concentrations at greater distances $(60-80 \mathrm{~km})$ downwind of the city of Berlin. In this region, the model underestimated the observed ozone concentrations by $10-15 \mathrm{ppb}$. Statistical investigation of the uncertainties inherent in the DRAIS model (Nester and Panitz, 2004) with respect to ozone shows that such deviations occur during daytime in some $25 \%$ of the cases compared. Although this is not a rare incidence, there seems to be a defect in the model proper or in the model parameters, because this deviation is restricted to one particular region.

The main purpose of this investigation is to identify possible reasons for the deviations between the observed and the calculated ozone concentrations in the city plume at greater distances. Also, it is of general interest to quantify those model parameters which could most likely be responsible for the deviations. In order to determine the most relevant parameters, a sensitivity analysis was carried out.

Sensitivity studies for CTM's have already been carried out in order to quantify the impact of parameter modifications on air quality, especially the peak ozone concentration. Usually, these studies are based on emissions and/or boundary conditions as model parameters (Palacios et al., 2002; Hogrefe et al., 2004; Dufour et al., 2005). These studies are based on different parameter scenarios. They do not calculate sensitivities related to individual species at certain grid points of the model. In order to perform such detailed sensitivity analysis usually adjoint modelling is applied often together with data assimilation. A fundamental sensitivity study using the adjoint method with emissions as parameter was published by Elbern et al. (2000). Sensitivity studies with distance functions based on ozone concentrations were carried out by Elbern and Schmidt (2001), using the initial species concentrations as model parameter, and by Schmidt and Martin (2003) with the emissions as parameter. Other studies of this kind were published by Vautard et al. (2000) and Vautard et al. (2003), based on data from the Paris region. Menut (2003) investigated the sensitivity of a greater number of relevant parameters on the ozone concentration in Paris.

The aim of the sensitivity analysis and data assimilation presented in this paper differs from those of the studies mentioned above. It is based on a distance function related to the ozone concentrations at two stations located in the city plume of Berlin and four different parameter sets. The latter are the initial and the boundary conditions of the species concentrations, emissions, and reaction rates. The sensitivities are calculated at each grid point and for all species considered in the model. This study goes into more details than investigations carried out so far.

The most effective method to determine sensitivities of a distance function with respect to a great number of para- meters is the application of the adjoint DRAIS model, which had been developed for this specific purpose. Besides determining sensitivities, simplified 4-D data assimilation was carried out to identify those parameter uncertainties, which probably cause the discrepancies between the measured and the simulated ozone concentrations.

\section{Simulations by the KAMM/DRAIS model and results}

\subsection{The KAMM/DRAIS model system}

The KAMM/DRAIS model system (Fig. 1) consists of the meteorological model KAMM (Adrian and Fiedler, 1991) and the dispersion model DRAIS (Nester and Fiedler, 1992). $\mathrm{KAMM}$ is a non-hydrostatic Eulerian model solving the Navier-Stokes equations of motion, the continuity equation, and the heat equation. It calculates the space and time dependent distributions of the wind-, temperature-, humidity, and turbulence fields in a terrain following coordinate system, which allows better resolution close to the ground than at higher levels. The model is driven by a geostrophic, hydrostatic basic state representing the large-scale synoptic conditions. Furthermore, nudging fields of wind and temperature can be incorporated into the KAMM model. A soilvegetation model (Schädler et al., 1990) describes the interaction between the soil and the atmosphere. It calculates the fluxes of heat and humidity in the soil, between the soil and the vegetation, and between the vegetation and the atmosphere as well as the momentum flux to the ground.

The model DRAIS solves the diffusion equation on an Eulerian grid using the same terrain following coordinate system as the KAMM model. It calculates the concentration distributions of all chemical species considered in the gas phase reaction mechanism RADM2 (Stockwell et al., 1990). This mechanism takes into account 158 reactions among 62 species, 21 of them are photolytic reactions. It explicitly integrates 41 species concentrations. Eighteen short-lived substances are considered to be in a quasi steady state. Methane, oxygen, and nitrogen are held constant with appropriate values. The dry deposition distributions of the different species are calculated using their dry deposition velocities (Baer and Nester, 1992), which are parameterized by a big-leaf multiple resistance model.

A local first order approach is chosen for vertical diffusion in the stable and neutral boundary layer. A non-local similarity approach is used in the convective boundary layer (Degrazia, 1988).

Initial and boundary conditions for the DRAIS model can be derived either from concentration measurements or from the results of larger scale models. The necessary emission data comprise anthropogenic and biogenic emissions. The anthropogenic emissions are input data, whereas the biogenic ones, which depend on land-use, temperature and radiation, 


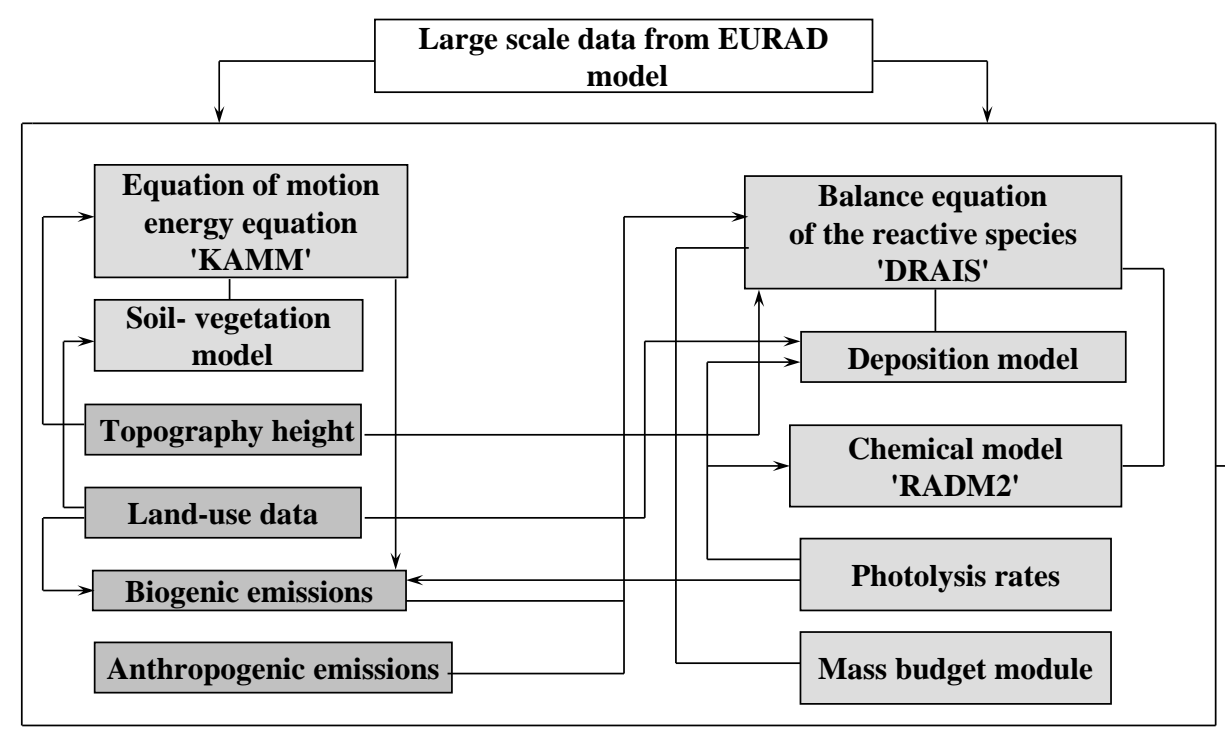

Wind, temperature, humidity, turbulence, radiation Concentration, deposition and mass budgets of the species

Fig. 1. Schematic representation of the KAMM/DRAIS model system.

are calculated in the model for each time step (Vogel et al., 1995).

A special module can be employed to calculate the components of the mass budget (emissions, advective and turbulent fluxes, deposition, and chemical transformations) in predefined volumes for all species considered in the model (Panitz et al., 1997).

\subsection{Simulations}

Simulations with the KAMM/DRAIS model system were carried out for 20 July 1998. The model domain had a size of $200 \mathrm{~km} \times 200 \mathrm{~km}$. The city of Berlin was located in the centre of the domain. Horizontal grid resolution was $2 \mathrm{~km}$. The external forcing for the KAMM model and the initialand boundary conditions for the species concentrations in the DRAIS model were determined from the results of the European scale model EURAD (Ebel et al., 1997). The grid size for this simulation was $18 \mathrm{~km}$. Only the ozone profile at the upper levels $(1.5-5 \mathrm{~km})$ was modified in line with the measurements carried out by the IBUF aircraft (Corsmeier et al., 2002). The emission data for this episode were provided by IER, Stuttgart. Land use and topography data were taken from the database supplied by IMK-IFU, GarmischPartenkirchen.

The ozone concentration distribution near ground level at 15:00 UTC on 20 July 1998, shows a pronounced ozone plume downwind of the city of Berlin (Fig. 2). The maximum ozone concentration in this plume is $68 \mathrm{ppb}$. It occurs at a distance of about $70 \mathrm{~km}$. Air masses with high ozone concentrations are transported over the southern boundary of the model domain.

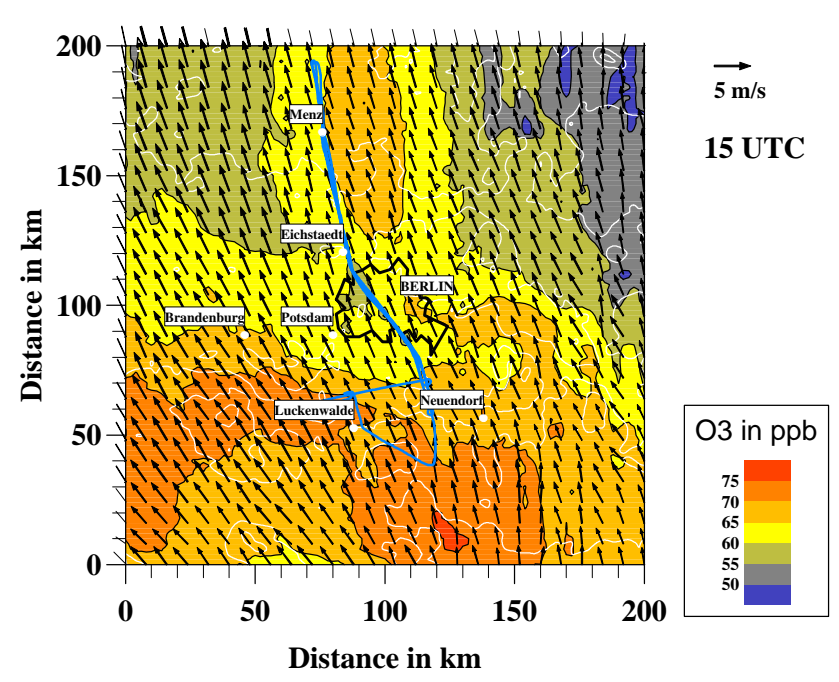

Fig. 2. Wind and ozone concentration fields near ground level for 20 July 1998 and afternoon flight track of the IBUF aircraft.

The diurnal ozone concentration cycles at two stations are presented in Fig. 3. At the Eichstaedt station, roughly $30 \mathrm{~km}$ downwind of the city centre of Berlin, the simulated ozone concentrations fit measurements quite well. However, at Menz station, about $70 \mathrm{~km}$ downwind of the city centre, the simulated ozone concentrations underestimate the measured ones. A similar result is obtained when comparing the ozone concentrations measured along the flight track of the IBUF aircraft (see Fig. 2) with the corresponding simulated concentrations. The flight track begins on the upwind side about $50 \mathrm{~km}$ southwest of Berlin, crosses the city, and it ends 

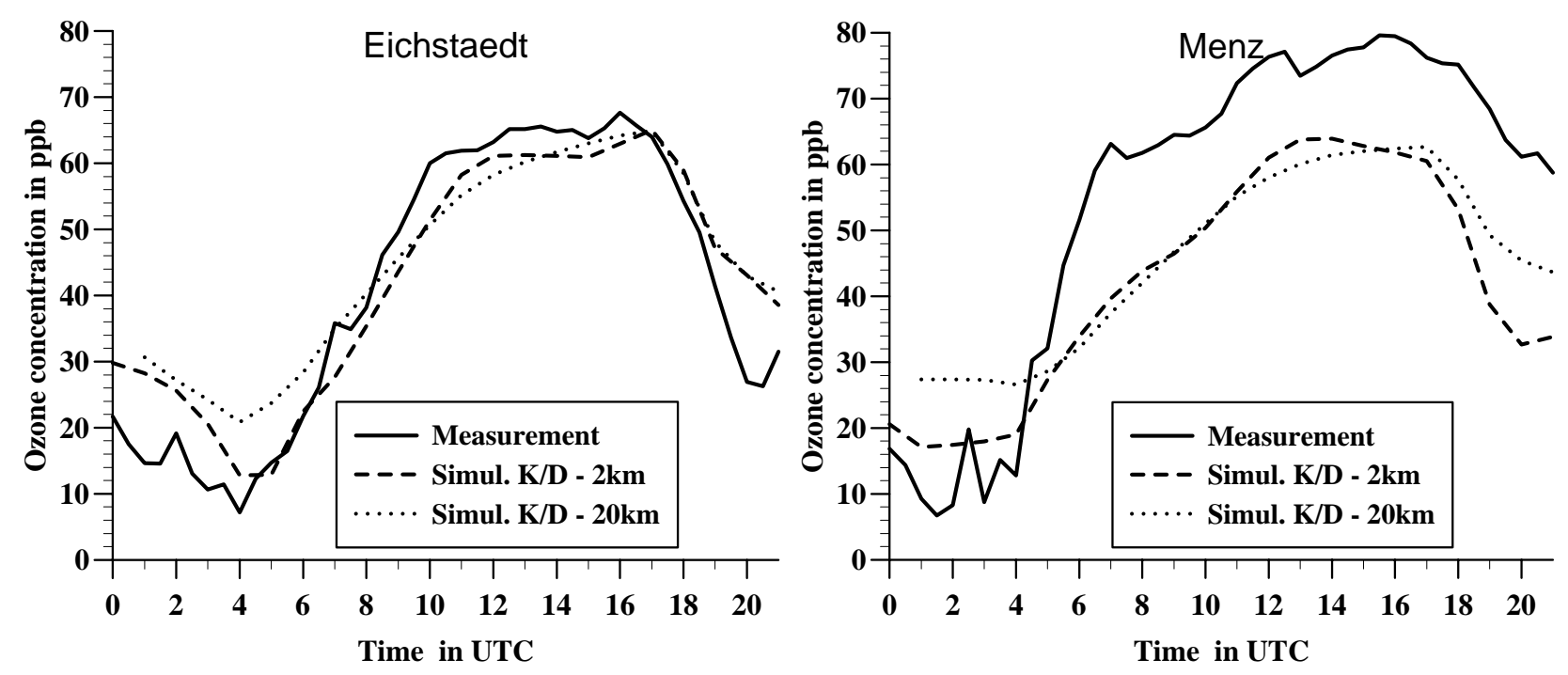

Fig. 3. Diurnal cycle of ozone concentration measured at ground level for the Eichstaedt and Menz stations compared to the results simulated with $2 \mathrm{~km}$ and $20 \mathrm{~km}$ grid resolution (see Sect. 3.2).

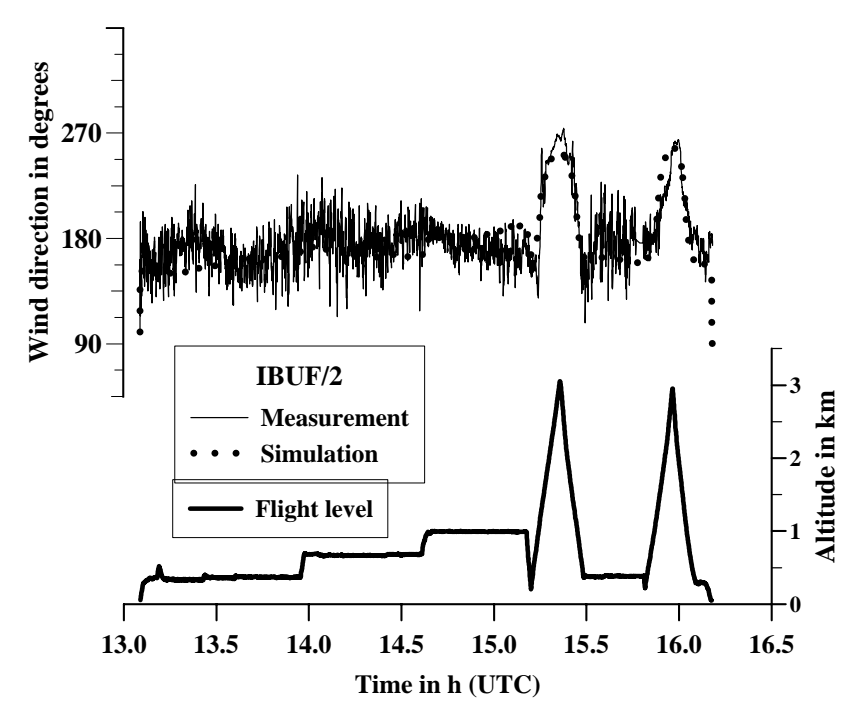

Fig. 4. Comparison of wind direction along the flight track of IBUF.

about $100 \mathrm{~km}$ downwind. Along this flight track, the aircraft flew at different altitudes. As can be seen from Fig. 4, the wind direction measured during the flight is simulated well by the model. A similar agreement is found for the wind speed, the temperature and the humidity. The simulated ozone concentration along the flight track also agrees quite well with the observations, except for two time periods (13.8 UTC and 15.1 UTC). During these two periods the aircraft flew in the area around and north of Menz where the model underestimates the measured ozone values by about 10-15 ppb (Fig. 5), while the meteorological conditions are simulated well.

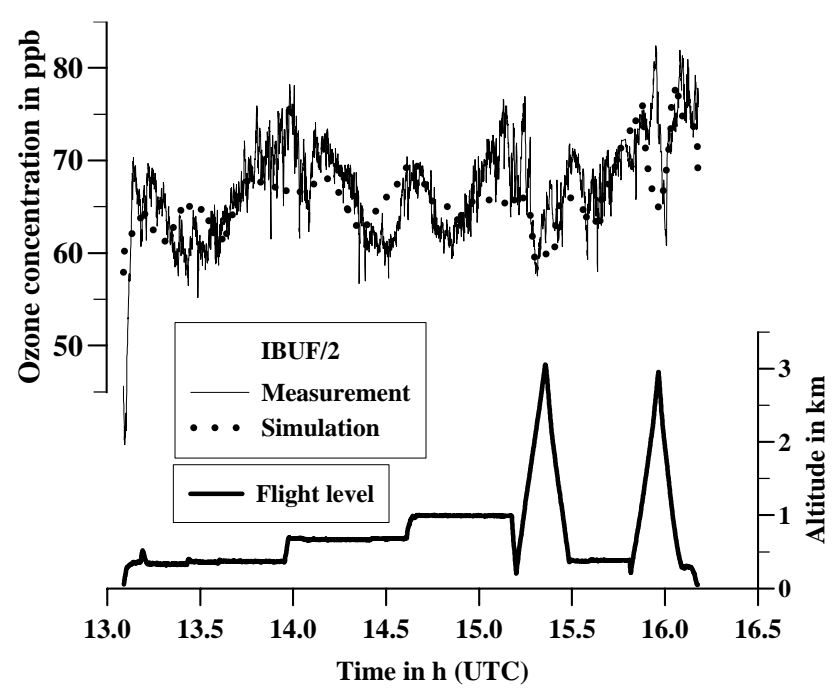

Fig. 5. Comparison of ozone concentration along the flight track of IBUF.

\subsection{Mass budget components of ozone in four layers over three regions}

The mass budget module in the KAMM/DRAIS model calculates the contributions of different processes to the change in the mean concentration in a predefined volume (Fig. 6). Production and loss terms are marked $\mathrm{P}$ and $\mathrm{L}$, respectively. More details are published in Panitz et al. (2002).

The calculations were performed for three regions (Fig. 7). The first region comprises the city of Berlin, two others are located north of the city. The ozone plume of the city crosses 


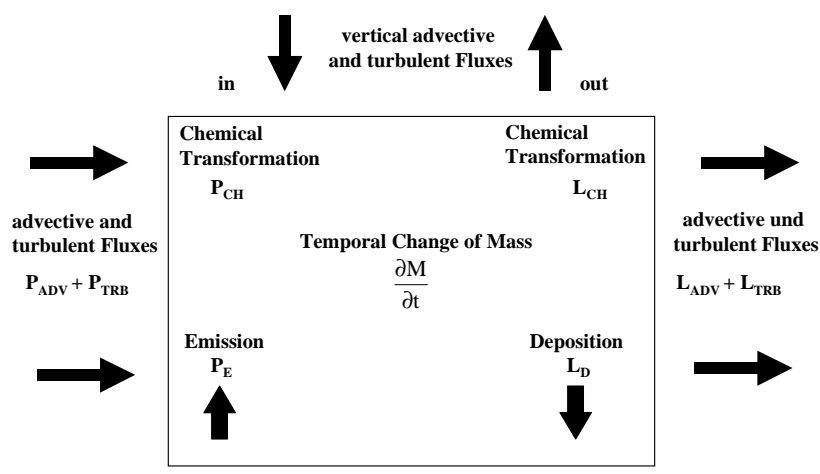

Fig. 6. Illustration of mass budget components.

these two regions during the afternoon. The atmospheric column over each region was divided into four vertical layers:

Layer 1: $2000 \mathrm{~m}-5000 \mathrm{~m}$ (free troposphere)

Layer 2: $1200 \mathrm{~m}-2000 \mathrm{~m}$ (upper boundary layer)

Layer 3: $75 \mathrm{~m}-1200 \mathrm{~m}$ (lower boundary layer)

Layer 4: ground-75 m (surface layer)

These layers have been chosen with respect to the boundary layer structure during the afternoon, when the aircraft measurements took place. They have to be the same over the whole simulation period in order to allow a comparison of the results. Although all mass budget components were determined, only the changes in ozone concentration due to chemical transformations are presented. Determining this quantity was one of the purposes of the experiment. Figure 8 shows the hourly change in the chemical ozone net production rate in layer 3 above all regions. During the afternoon hours, the net production rates are nearly the same in the regions 1 and 2, whereas the rate is obviously lower in region 3.

During the afternoon the ozone net production in the urban plume reaches a level of about $6.5 \pm 1.0 \mathrm{ppb} / \mathrm{h}$, as derived from aircraft measurements on the downwind side of the city (Corsmeier et al., 2002). The aircraft flew at different levels in the lower mixing layer (layer 3 in our mass balance calculations), and it crossed regions 2 and 3 several times. The simulated ozone net production rate has been averaged over the time periods when the aircraft crossed the two regions, resulting in $5.1 \mathrm{ppb} / \mathrm{h}$ and $3.5 \mathrm{ppb} / \mathrm{h}$ for regions 2 and 3 , respectively. For region 2 this is still in acceptable agreement with the value derived from the aircraft measurements. The ozone net production rate in region 3 is obviously too low. For the city region, values of $4.5 \pm 1.0 \mathrm{ppb} / \mathrm{h}$ and $5.0 \mathrm{ppb} / \mathrm{h}$ are calculated for the measured and the simulated ozone net production rates, respectively.

The results of this comparison give an indication that the reason for the underestimation of the observed ozone con-

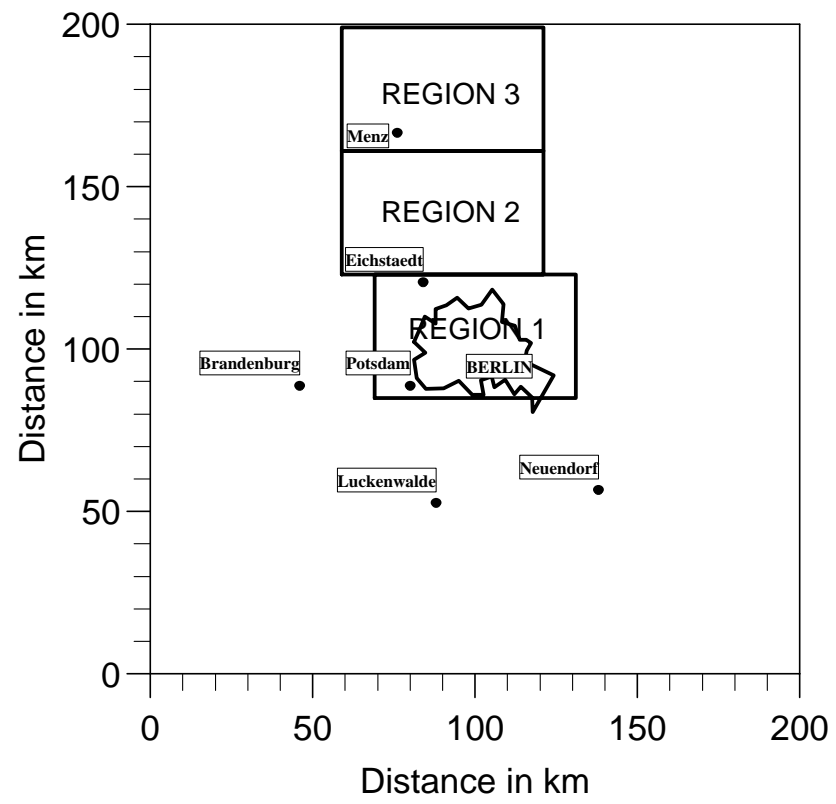

Fig. 7. Arrangement of regions.

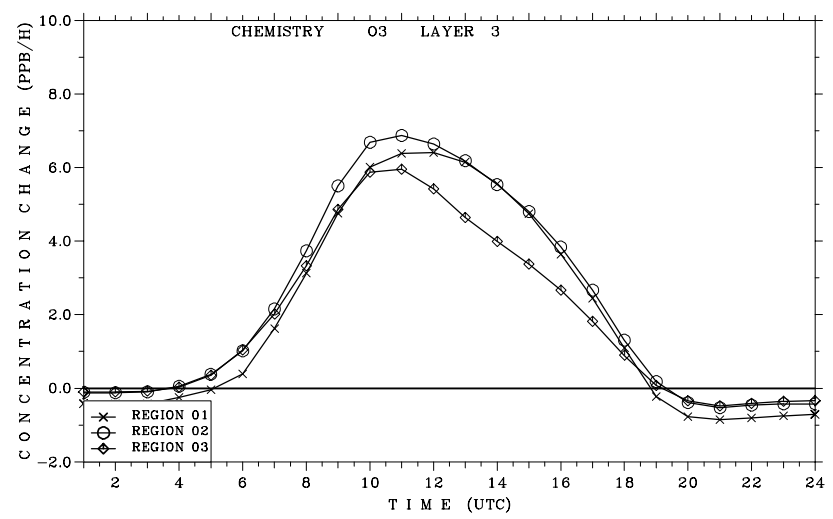

Fig. 8. Diurnal cycle of ozone production rate caused by chemical reactions in layer 3 over three regions.

centrations at Menz by the model might be caused by too low ozone net production rate in the city plume at farther distances.

\section{Sensitivity analysis}

A sensitivity study was performed to find the reasons of the discrepancies identified in ozone concentrations. In our case, sensitivity is defined as the parameter derivative $\partial J / \partial p$ of a distance function, $J$. This function is defined as

$J=\sum_{l=1}^{2} \sum_{i=8}^{16}\left(C_{s, i}-C_{m, i}\right)_{l}^{2}$ 
with:

$C_{s, i}:$ simulated ozone concentration for the time $i$ (UTC),

$C_{m, i}:$ measured ozone concentration for the time $i$ (UTC),

$l=1$ : at Eichstaedt station (see Figs. 2 and 3),

$l=2$ : at Menz station (see Figs. 2 and 3 ).

The value of the distance function describes the quality of the agreement between the measured and the calculated ozone concentrations at the stations Eichstaedt and Menz during daytime. The lower the value is, the better the agreement. The ozone concentrations at both stations were selected as representative for the ozone concentrations in the plume closer and farther away from the city of Berlin.

Four parameters are selected for the analysis:

- Emissions,

- initial species concentrations,

- boundary values of species concentrations,

- reaction rates

Meteorological variables are not considered as model parameters, because, on one hand, we put much effort into the modelling of the meteorological conditions. In order to get a good agreement between measured and simulated meteorological quantities, several simulations with the meteorological model KAMM have been carried out using the nudging procedure being part of the model system. Wind speed and direction as well as temperature and humidity along the flight route of the IBUF aircraft are well simulated. The boundary layer height derived from the aircraft measurements may vary between $1500 \mathrm{~m}$ and $1800 \mathrm{~m}$ compared to the modelled value of about $1600 \mathrm{~m}$.

On the other hand, from the model's underestimation of the net ozone production rate in the city plume at farther distances it can be assumed, that parameters of the chemistry model are probably responsible for the ozone deficits found at Menz station.

Furthermore, the BERLIOZ episode we are considering has also been modelled with the EURAD model. This model uses the same chemical mechanism as the DRAIS model does. But the parameterizations in the meteorological part are different from those in the KAMM model. However, the results of both model systems show similar ozone concentrations at the station Menz. This is an additional indication that the deficit, we are looking for, is not caused by the meteorological model.

Several possibilities exist to calculate the sensitivities described before. Since we are interested in the sensitivities of the distance function related to a large number of parameters at all grid points of the model domain, it is necessary to have a methodology that allows calculating these sensitivities simultaneously. Such an effective way of calculating the sensitivities is the application of an adjoint model. Although the development of such a model is not easy and a long lasting task, it has been carried out resulting in the adjoint DRAIS model.

\subsection{The adjoint DRAIS model}

The sensitivities described before can be calculated with the tangent linear model, which is determined by building the derivative of the variables of the original model related to a model parameter, $\partial C / \partial p$. Because the sensitivities of the distance function depend on these variables, they can be calculated using the results of the tangent linear model. The disadvantage of this method is the fact that for each parameter a separate simulation has to be carried out. It would be much more effective if the sensitivities of the distance function related to many parameters can be calculated simultaneously. Using the adjoint model instead of the tangent linear model allows such an effective calculation. The adjoint model can be derived from the tangent linear model by applying the relation between both model operators and variables, which is given by Eq. (2).

$$
<g^{*} ; M^{\prime} g>=<M^{*} g^{*} ; g>
$$

where

$<A ; B>$ is the symbol of the inner product of the expressions $A$ and $B$.

$g=$ gradient, $(\partial C / \partial p)$, which is the variable in the tangent linear DRAIS model

$g^{*}=$ adjoint gradient, which is the variable in the adjoint DRAIS model

$M^{\prime}=$ model operator of the tangent linear DRAIS model $M^{*}=$ model operator of the adjoint DRAIS model.

The derivation of the adjoint model equations is not the task of this paper. There are several publications (Talagrand and Courtier, 1987; Pudykiewicz, 1998; Ustinov, 2001), where the procedures are presented in more detail.

Although programmes exist for automatic transformation of the original code into the tangent linear and the adjoint codes (TAMC, Giering and Kaminski, 1998; Odyssee, Rostaing et al., 1993), the adjoint DRAIS model was developed manually. Unlike the adjoint CHIMERE model (Schmidt and Martin, 2003), however, it is not coded line by line in accordance with the principles of automatic transformation. The adjoint DRAIS model is derived from the tangent linear model of DRAIS, which uses the same difference approximations as the original model. Equation (2) is applied to determine the adjoint DRAIS model equations as in the procedure given by Ustinov (2001). Instead of differential equations, difference equations are used to obtain the adjoint difference equations. This is advantageous because the results of the sensitivity analysis using the adjoint model can be better compared with those achieved when applying the tangent linear and the original models. The structure of the adjoint DRAIS model is similar to that of the original model and 
the tangent linear model. Of course, the subprograms are arranged in inverse order. As far as possible the subprograms are coded corresponding to the original model. These manually coded programmes offer the advantage of clear structures and can be optimized with respect to storage requirements and computing time (Elizondo et al., 2002).

\subsubsection{Advection scheme}

In the original DRAIS model, a second-order non-oscillatory Flux Corrected Transport (FCT) advection scheme with limiters is implemented. In addition, divergence correction is used. To avoid problems in the adjoint scheme (Thuburn and Haine, 2001), this scheme was used without limiters. It is now linear and of second order, but no longer monotone. The results of the original and the modified advection schemes differ only slightly. The distance function (Eq. 1) decreases by only approx. $3 \%$. The adjoint advection term was derived from Eq. (2) with the modified difference scheme used for advection. It differs slightly from the tangent linear advection scheme with inverse velocities. The divergence correction term is omitted in the adjoint advection scheme.

\subsubsection{Diffusion scheme}

Diffusion is approximated in the original and the tangent linear model by central differences. This approximation can also be applied in the adjoint DRAIS model using the adjoint deposition velocity.

\subsubsection{Chemical reaction terms}

The chemical reaction terms in the original DRAIS model are non linear. They are linearized in the tangent linear model. The linearized chemical reaction terms can be written as an $\mathrm{n} \times \mathrm{n}$ matrix, where $\mathrm{n}$ is the number of variables, $\partial C_{k} / \partial p$, in the tangent linear model.

$d\left(\partial C_{k} / \partial p\right) / d t=\sum_{i=1}^{n} A_{k, i} \partial C_{k, i} / \partial p \quad k=1, n$

These variables are the model parameter derivatives of the chemical species concentrations in the original DRAIS model. In the DRAIS model, 41 transported and 18 diagnosed species are considered, thus, $n=59$. In the adjoint DRAIS model, the transpose of this matrix is employed. The procedure to solve Eq. (3) is the same in both models and corresponds to the QSSA method used to integrate the RADM2 chemical mechanism (Chang et al., 1987).

\subsubsection{Test calculations}

The correctness of the adjoint DRAIS model was tested by sensitivity calculations for a large number of model parameters at different grid points. The sensitivities of the distance function calculated by applying the adjoint DRAIS model are compared with the sensitivities derived from two simulations with the original model using the parameter values, $p \pm \Delta p$. The comparisons have been performed not only at those grid points with the highest sensitivity values, but also at a lot of other grid points. Of course, the results were not identical. After the test calculations the relative error between both results was less than $1 \%$, at least for the higher sensitivity values.

\subsection{Results of sensitivity analysis}

The sensitivity of the distance function relative to the parameters mentioned above is calculated for each grid point. For these calculations, the grid size was increased by a factor of 10 because of the large number of data to be stored. In addition, the simplified data assimilation (Sect. 4) takes a lot of computing time. The increase in grid size allows a large number of simulations to be run with acceptable storage and run times. Also, more test calculations can be performed. The KAMM/DRAIS simulations (Sect. 2.2) were repeated with a coarse horizontal resolution of $20 \mathrm{~km}$. During the day, differences between the diurnal cycles of ozone concentrations resulting from simulations with grid resolutions of $2 \mathrm{~km}$ and $20 \mathrm{~km}$ are rather small at both stations, Eichstaedt and Menz (Fig. 3). Therefore, it may be sufficient to calculate sensitivities with the coarser grid.

The sensitivity, $S_{p}$, of the distance function, $J$, relative to a model parameter $p$ is defined as:

$S_{p}=\partial J / \partial p$

In the analysis below, the parameter, $p$, is replaced by the reference value, $p_{o}$, multiplied by a factor, $f_{p}$, which is the new parameter replacing $p$.

$p=p_{0} \times f_{p}$

$\mathrm{p}_{o}$ is constant representing the original value applied in the reference DRAIS model simulation. This transformation is helpful for those parameters, which are time dependent like the emissions. By using $f_{p}$ instead of $p$, the sensitivity depends only on the level and not on the shape of the diurnal variation of parameter $p$. For a better comparison of the sensitivities this transformation was applied to all parameters.

The sensitivity (Eq. 4) is now defined as:

$S_{p}=\left(\partial J / \partial f_{p}\right) / p_{0}=S_{f p} / p_{0}$

with

$S_{f p}=\partial J / \partial f_{p}$.

The sensitivity, $S_{f p}$, used below, is now related to the parameter, $f_{p}$.

The simulation starts at 00:00 UTC and runs till 05:00 UTC. The results of this first run are used as initial conditions for a second one running from 05:00 UTC till 21:00 UTC. The time of initialization for the calculation of the sensitivities is 05:00 UTC. This initialization time was 


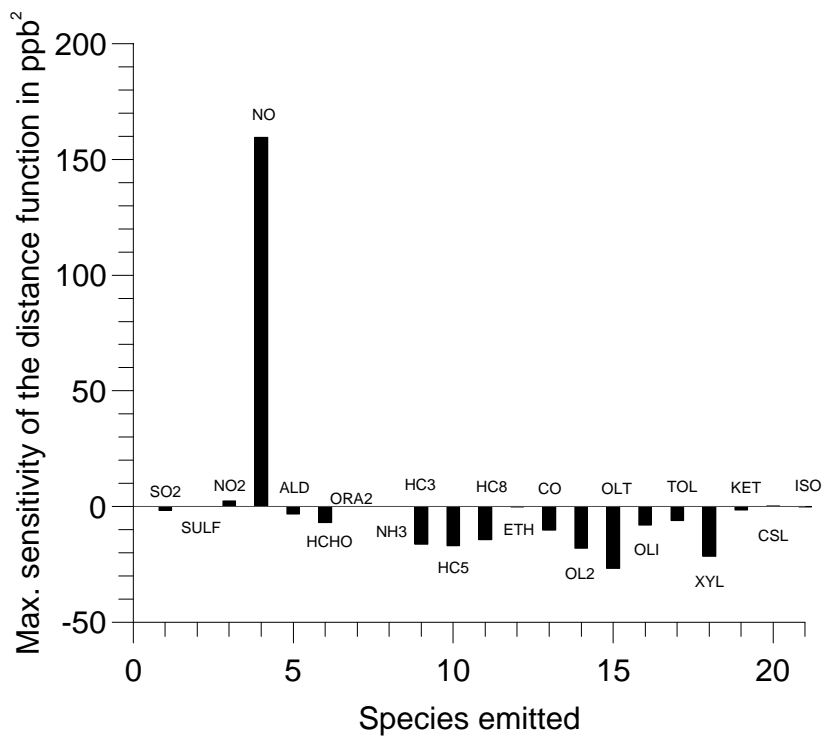

Fig. 9. Maximum sensitivity of the distance function related to the emissions.

chosen, because it is short after sunrise, when daytime chemistry is activated. Additionally, the ozone concentration calculated at the station Menz is still close to the measured value. Deviations occur only later during the day.

\subsubsection{Emissions}

The sensitivity of the distance function related to emissions,

$S_{f e}=\partial J / \partial f_{e}$

is calculated for all grid points where emissions occur, and for all species emitted. The local maximum of $S_{f e}$ for each species, integrated over the time between 05:00 UTC and 16:00 UTC, is plotted in Fig. 9 arranged by the numbers they posses in the emission inventory of the original DRAIS model (see Appendix A). Negative sensitivity means that an increase in emissions of this species reduces the distance function, thus furnishing better agreement of the measured and the simulated ozone concentrations at the stations Eichstaedt and Menz. As the distance function, $J$, depends on the ozone concentrations, it is no surprise that NO is the most sensitive species. High values of positive sensitivity related to NO emissions occur in the area of the city of Berlin close to the ground and also in higher levels. Negative sensitivities occur also close to the ground but upwind of the city. But the highest absolute value occurring in these regions is more than a factor 10 lower than the maximum sensitivity of about $160 \mathrm{ppb}^{2}$ that is found in the city of Berlin.

The main sensitivities related to the hydrocarbons appear close to the ground in and around the city of Berlin. Only negative sensitivities are calculated. The maximum values of the sensitivities relative to hydrocarbons are located at the same grid point in the centre of the model domain. If the peak values are summed up, the absolute value is about $10 \%$ lower than the maximum sensitivity relative to NO. This means that the influence of the hydrocarbon emissions on the distance function is nearly the same as the influence of the NO emissions, but with inverse sign. The peak sensitivity related to alkenes emissions is higher than those of alkanes, carbonyls, and aldehydes. The sensitivity related to $\mathrm{CO}$ emissions corresponds to that of aldehydes. To obtain a lower distance function, $\mathrm{NO}$ emissions must be reduced while hydrocarbon and $\mathrm{CO}$ emissions must be increased. Beside the local maximum sensitivities those integrated over the whole domain are calculated. Based on absolute values, the sensitivity ranking does not change. It is the same as for the consideration of local maxima. But the sensitivity relative to $\mathrm{NO}$ emissions is nearly a factor of two higher than the absolute value of the sensitivity related to the hydrocarbon emissions.

\subsubsection{Initial species concentrations}

The sensitivity of the distance function relative to initial species concentrations is defined as in the previous case:

$S_{f i}=\partial J / \partial f_{i}$

The sensitivities are calculated at each grid point for all 41 species listed in Appendix A. Again, the local maximum sensitivity for each species integrated over the time between 05:00 UTC and 16:00 UTC is considered (Fig. 10). As the distance function depends on the ozone concentration, ozone is expected to be the most sensitive species. The local peak sensitivity for ozone $\left(-123 \mathrm{ppb}^{2}\right)$ is really the dominant sensitivity. The peak value occurs west of the city centre in a height of about $750 \mathrm{~m}$ above ground. Further considerable values are found upwind of the city, also at higher levels. The second species in the ranking list is PAN. Its peak sensitivity value is about a factor of 20 lower than that for ozone. Thus, it can be concluded that modifications of the concentrations of all non ozone species have only a minor influence on the distance function. This statement is confirmed by the sensitivities integrated over the model domain. A special role plays the sensitivity with respect to $\mathrm{NO}_{\mathrm{x}}$ whose peak value is positive in contrast to the sensitivities for all other species. Considerable positive sensitivities related to $\mathrm{NO}_{\mathrm{x}}$ are found in and around Berlin up to a height of $500 \mathrm{~m}$. In still higher levels the sensitivities are negative. Close to the ground the sensitivities related to the initial $\mathrm{NO}_{\mathrm{x}}$ concentrations show the same positive sign as for the $\mathrm{NO}_{\mathrm{x}}$ emissions. But in the upper levels there is another regime, where an increase of the $\mathrm{NO}_{\mathrm{x}}$ concentration causes a production of ozone downwind of the city. Because of these two different regimes, the sensitivity for $\mathrm{NO}_{\mathrm{x}}$ integrated over the model domain does not reflect the real importance of this species compared to the other non ozone species. Therefore, its place in the ranking (absolute values) of the integrated sensitivities is below that of the ranking list based on the local peak sensitivities. 


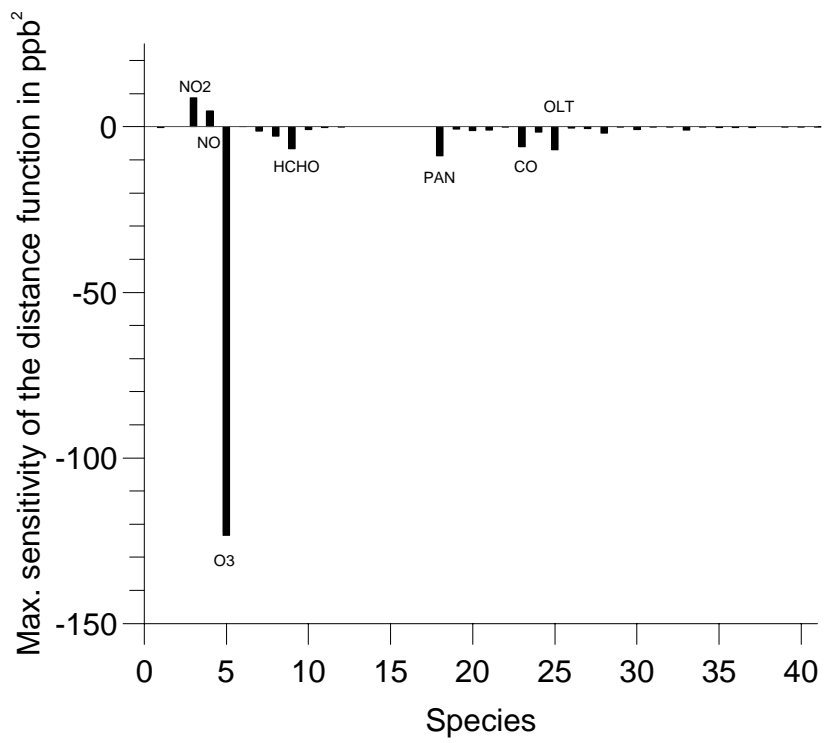

Fig. 10. Maximum sensitivity of the distance function related to the initial conditions.

\subsubsection{Boundary species concentrations}

The sensitivity with respect to the boundary species concentrations is defined in the same way as for the previous parameters.

$S_{f b}=\partial J / \partial f_{b}$

Boundary values are taken into account for those 41 species listed in Appendix A. Figure 11 shows the maximum sensitivity related to all these species. As expected, the most sensitive species again is ozone. Two maxima occur at the western and southern boundary. The negative peak value $\left(-189 \mathrm{ppb}^{2}\right)$ is located in a height of $1900 \mathrm{~m}$ above ground at the western boundary, about $80 \mathrm{~km}$ north of the south-west corner of the model domain. An absolute sensitivity maximum in such an altitude at the western boundary is only found for ozone. It can only be explained by the fact that ozone is transported to the area of Menz in the upper layers, and then mixed down to the ground. The secondary peak value for ozone $\left(-98 \mathrm{ppb}^{2}\right)$ is located $60 \mathrm{~km}$ east of the south-west corner in a height of $1100 \mathrm{~m}$. Between these two peaks, further sensitivities with rather high values occur along the western and southern boundary. Corresponding to the results for the initial conditions, the maximum sensitivity for PAN is about a factor of 20 lower than that for ozone. It is located at the southern boundary, $80 \mathrm{~km}$ east of the southwest corner in a height of about $700 \mathrm{~m}$ above ground. The maximum sensitivity related to the hydrocarbons is lower than that for the initial hydrocarbons. The peak sensitivity values are also located at the southern boundary in altitudes between 100 and $700 \mathrm{~m}$. Different to the result for the initial conditions is the sensitivity for $\mathrm{NO}_{\mathrm{x}}$. No positive sensitivities

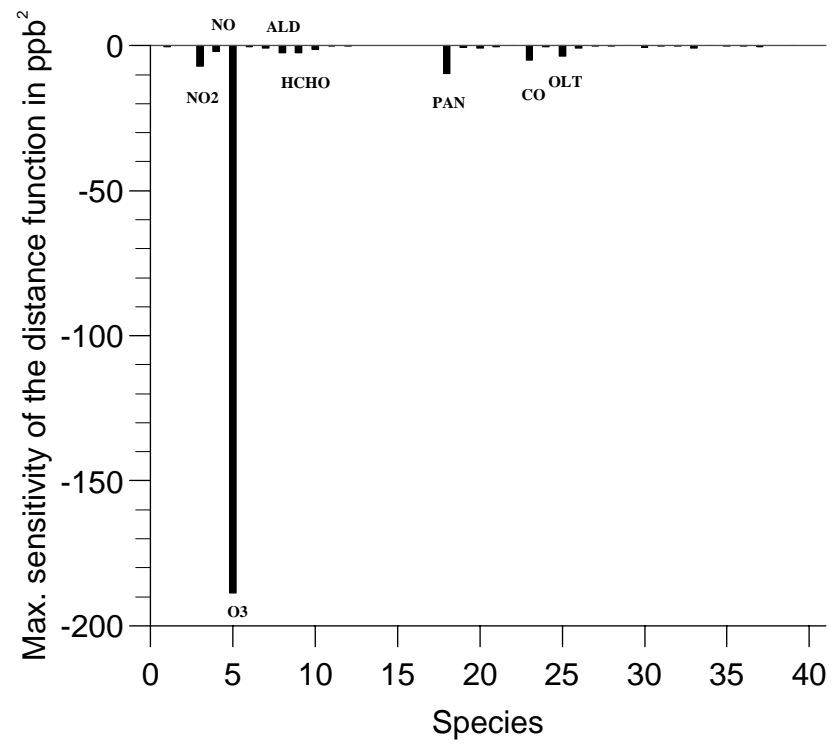

Fig. 11. Maximum sensitivity of the distance function related to the boundary conditions.

are calculated and the shape of the distribution of the sensitivities at the southern boundary is similar to that of PAN. At the southern boundary there is a low $\mathrm{NO}_{\mathrm{x}}$ concentration regime resulting in negative sensitivity values for $\mathrm{NO}_{\mathrm{x}}$. If we look to the sensitivities for the different species concentrations integrated over the model domain, the ranking of the absolute values is similar to that for the local peak sensitivities. This means that the integrated sensitivities provide no important further information. The sensitivity values for all species are negative. Therefore, a decrease of the distance function requires an increase of the concentrations at the western and southern boundary.

\subsubsection{Photolysis rates}

The sensitivities of the distance function with respect to the photolysis rates,

$S_{f p}=\partial J / \partial f_{p}$

are calculated at all grid points and for all 21 photolysis reactions (Stockwell, 1990). The local maximum values for each photolysis rate integrated over the time between 05:00 UTC and 16:00 UTC are plotted in Fig. 12. Reaction (1) describes the photolysis of $\mathrm{NO}_{2}$ to $\mathrm{NO}$ and $\mathrm{O}_{3}$ (see Table 1). This is the most important photolysis reaction influencing the production of ozone. Therefore, it is not astonishing that the peak sensitivity for this reaction rate is the dominant one in Fig. 12. The local maximum sensitivity $\left(-172 \mathrm{ppb}^{2}\right)$ is located close to the ground in the area of Menz. Further high sensitivity values are found up to a height of $750 \mathrm{~m}$. Lower sensitivities are calculated at grid points south of the Menz area in the same layer, The next important reaction is the 
Table 1. Parameters modified in simplified data assimilation together with the lower and upper limits of $\mathrm{f}_{p}$ (*reactions additionally considered in the assimilation process).

\begin{tabular}{cccc}
\hline \multicolumn{4}{c}{ Emissions } \\
\hline Classes & Species group & Species name & Limit \\
\hline 1 & $\mathrm{SO} 2$ & Sulfur dioxide & $0.66-1.5$ \\
2 & $\mathrm{NO} 2$ & Nitrogen dioxide & $0.66-1.5$ \\
3 & $\mathrm{NO}$ & Nitric oxide & $0.66-1.5$ \\
4 & ALD+HCHO+KET & Carbonyls & $0.5-2.0$ \\
5 & HC3+HC5+HC8+ETH & Alkanes & $0.5-2.0$ \\
6 & CO & Carbon monoxide & $0.5-2.0$ \\
7 & OL2+OLT+OLI+ISO & Alkenes & $0.5-2.0$ \\
8 & TOL+XYL+CSL & Aromatics & $0.5-2.0$ \\
\hline
\end{tabular}

\begin{tabular}{cccc}
\hline \multicolumn{3}{c}{ Initial concentrations and boundary concentrations } \\
\hline $\begin{array}{c}\text { Species number } \\
\text { in the model }\end{array}$ & Species & $\begin{array}{c}\text { Limits of } \\
\text { init. conc. }\end{array}$ & $\begin{array}{c}\text { Limits of } \\
\text { bound. conc. }\end{array}$ \\
\hline 3 & NO2 & $0.75-1.3$ & $0.6-1.4$ \\
4 & NO & $0.66-1.5$ & $0.6-1.4$ \\
5 & O3 & $0.83-1.2$ & $0.6-1.4$ \\
9 & HCHO & $0.66-1.5$ & $0.6-1.4$ \\
18 & PAN & $0.66-1.5$ & $0.6-1.4$ \\
23 & CO & $0.66-1.5$ & $0.6-1.4$ \\
25 & OLT & $0.66-1.5$ & $0.6-1.4$ \\
\hline
\end{tabular}

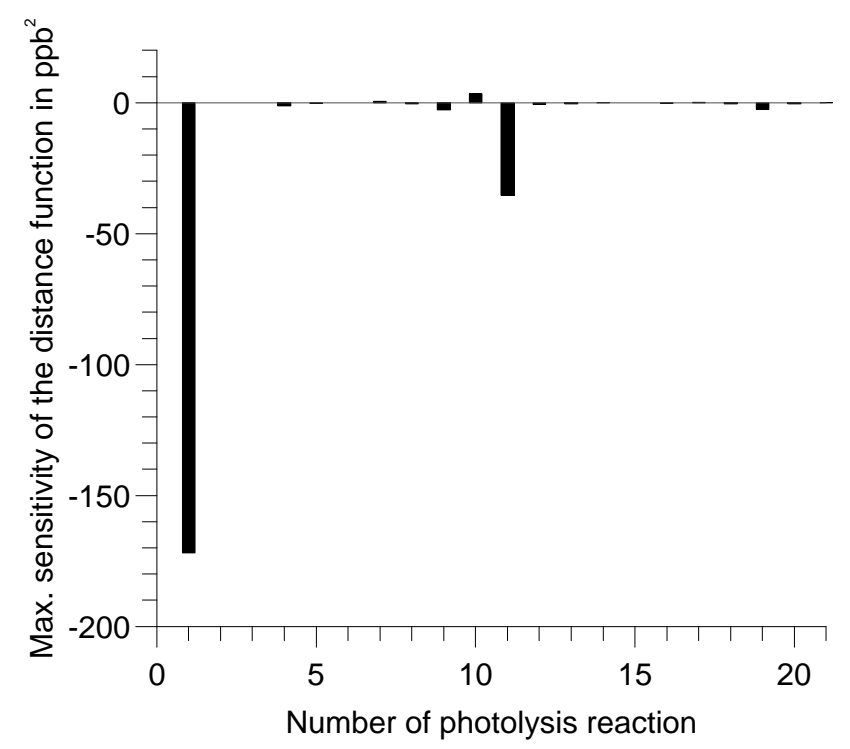

Fig. 12. Maximum sensitivity of the distance function related to the photolysis rates.

photolysis of formaldehyde $\left(\mathrm{CH}_{2} \mathrm{O}\right)$ to $\mathrm{HO}_{2}$ and $\mathrm{CO}$ (Reaction 11, Table 1), The peak sensitivity related to this photolysis rate occurs in the area of Menz in an altitude of $400 \mathrm{~m}$

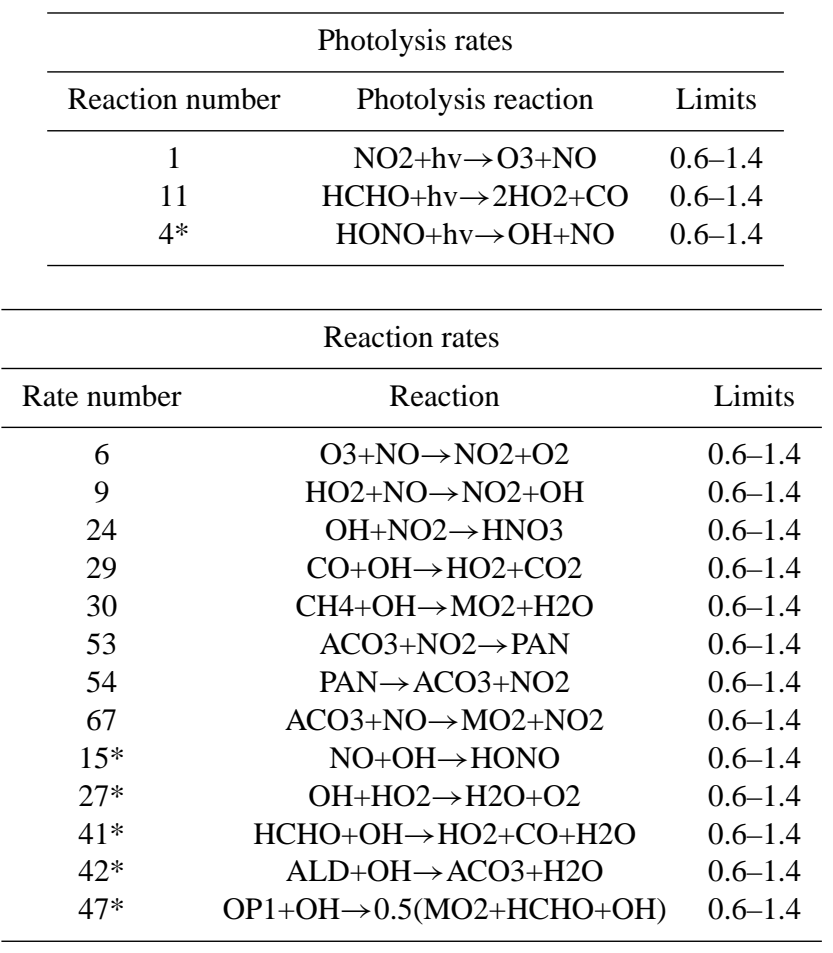

above ground. Further high sensitivities are calculated between the ground and $750 \mathrm{~m}$ in the area of Menz and south of it. The third place in the ranking of maximum sensitivities belongs to reaction number 10, the photolysis of $\mathrm{HCHO}$ to $\mathrm{H}_{2}$ and $\mathrm{CO}$. It is the largest positive maximum sensitivity. However, this peak sensitivity is already a factor of 10 lower than that for the photolysis rate number 11 . The sensitivities for the photolysis rates integrated over the model domain show the same ranking (Reaction 1, followed by 11 and 10). Only the ratios between the absolute values of the three integrated sensitivities are reduced by about $35 \%$ compared to the corresponding ratios of the local peak sensitivities.

\subsubsection{Reaction rates}

140 non photolytic reactions are considered in the RADM2 chemical mechanism. The sensitivities of the distance function related to these reactions rates

$S_{f r}=\partial J / \partial f_{r}$

integrated over the time between 05:00 UTC and 16:00 UTC are calculated at each grid point. The resulting local maximum sensitivities are plotted in Fig. 13. The eight dominant reactions are listed in Table 1 (the first eight reactions). As expected, the rate of the reaction between $\mathrm{O}_{3}$ and $\mathrm{NO}$ shows the highest sensitivity. The peak sensitivity is calculated in 
the area of Menz close to the ground. High values are also found up to an altitude of about $1500 \mathrm{~m}$. In this layer remarkable sensitivity values are also located south of the Menz area. As can be seen from Table 1, the dominant sensitivities are related to reactions with $\mathrm{NO}, \mathrm{NO}_{2}, \mathrm{PAN}$, and $\mathrm{OH}$. Out of the eight peak sensitivities, three have a positive sign (rate numbers 6, 24, and 53). They lead to a loss of ozone or $\mathrm{NO}_{2}$. The other reactions produce $\mathrm{NO}_{2}$ or other species being relevant in ozone production. The distributions of the sensitivities in the model domain related to the eight reactions show a shape similar to that belonging to the reaction between $\mathrm{O}_{3}$ and $\mathrm{NO}$.

The most relevant eight reactions based on the sensitivities integrated over the model domain and also their signs are the same as those derived from the local peak sensitivity values. Most of these reactions are also considered in the sensitivity study by Menut (2003).

\section{Variation of relevant parameters}

After calculation of the sensitivities it is possible to select the most relevant parameters that influence the distance function. The selection can be based on the peak sensitivities or on the sensitivities integrated over the model domain. In most cases both data bases provide the same result. But in those cases where the sensitivity distribution shows larger negative and larger positive values, the ranking of the integrated sensitivities does not represent the real importance of the corresponding parameter. Therefore, a ranking of the parameter relevance based on the absolute values of the local peak sensitivities is more reliable. The parameters selected are summarized in Table 1.

From the data in Table 1 it cannot be decided, which parameter is most likely responsible for the observed discrepancies in the ozone concentrations at the station Menz. In order to answer this question, we carried out simplified 4-D data assimilation. It was conducted to find out which parameter modifications are able to diminish discrepancies in ozone concentrations in the city plume of Berlin observed at greater distances. In this context simplified means that a background term in the distance function is not considered. This simplified data assimilation provides a lower distance function compared to one which takes a background term into account.

The main reason for using simplified data assimilation is the lower expenditure and the not (well) known error correlation matrix in the background term. The modified distribution of the relevant parameters in the model domain is less smooth than that calculated by data assimilation with background term. Because the main variations should be similar, the answer of the question risen before can be found also with the results of the simplified data assimilation. In order to avoid completely unrealistic results, parameter variation is

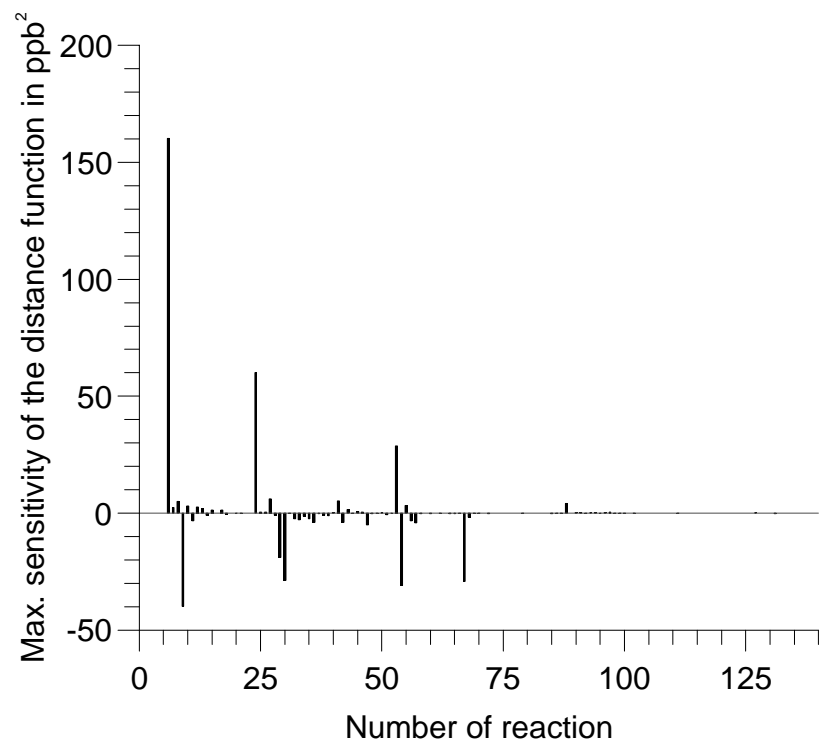

Fig. 13. Maximum sensitivity of the distance function related to the reaction rates.

limited. The limits for the different parameters are also listed in Table 1.

The limits for emissions are estimated from evaluations of the Augsburg project (Slemr et al., 2002). For $\mathrm{SO}_{2}, \mathrm{NO}$ and $\mathrm{NO}_{2}$ emissions, the same uncertainty factor of 1.5 is used. Thus, the lower limit of $\mathrm{f}_{p}$ is $1 / 1.5=0.66$ and the upper limit is 1.5. Hydrocarbon and $\mathrm{CO}$ emissions are more uncertain. Therefore, a value of 2.0 is chosen, which corresponds to a lower limit of 0.5 .

The limits for the initial concentrations are estimated in a similar way. For the initial NO concentration, the same limits are used as for the NO emissions, because the NO concentrations mainly depend on local emissions. Nester and Panitz (2004) showed that differences of $20 \%$ can occur between the measured and the simulated ozone concentrations. Therefore, an uncertainty factor of 1.2 is taken for ozone. The uncertainty in the initial $\mathrm{NO}_{2}$ concentration lies between the values for NO and those for ozone because it is influenced more by chemical processes and long range transport than the NO concentration. The uncertainty factor for the initial hydrocarbon concentrations should be lower than that of the emissions. Therefore, a value of 1.5 is chosen. This value is taken also for the initial concentrations of PAN and CO.

As it is very difficult to define individual limits for the different parameters, the same limitations were chosen for the boundary conditions and the reaction rates. For both parameter sets, a variation of $\pm 40 \%$ is allowed (Menut, 2003). In order to avoid unrealistic parameter modifications, this rough estimate of the limits seems to be acceptable.

All simulations with the modified parameters started at 05:00 UTC and ran till 21:00 UTC in the evening. 05:00 UTC was chosen as initialization time, because it is 


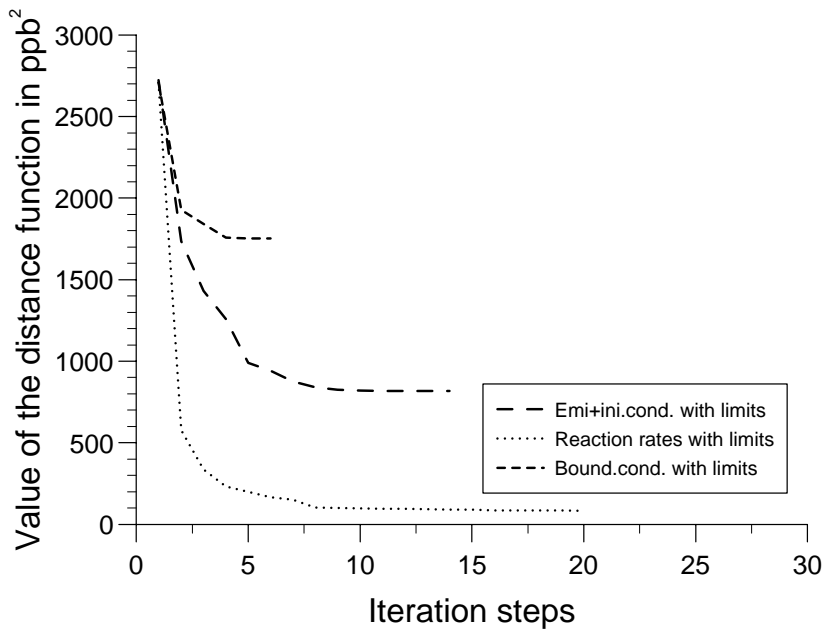

Fig. 14. Iterative reduction of the distance function.

short after sunrise, when daytime chemistry is activated. Additionally, the ozone concentration calculated at the station Menz is still close to the measured value. The assimilation window began at 08:00 UTC and ended at 16:00 UTC. Only in this time period, improved agreement between the measured and the simulated ozone concentrations at the stations of Eichstaedt and Menz is assured. It is interesting to see whether there is better agreement also between 05:00 UTC and 08:00 UTC as well as after 16:00 UTC.

Simplified data assimilation is carried out separately with i) the initial conditions together with the emissions, as recommended by Elbern and Schmidt (2002), ii) the boundary conditions, and iii) the reaction rates including photolysis rates., respectively. Iterative reduction of the distance function is performed by the conjugate gradient method using limits. The convergence of the distance function is plotted in Fig. 14.

The boundary conditions furnish the highest minimum of the distance function. This result is not surprising, because it takes more than $3 \mathrm{~h}$ that modifications in the boundary conditions cause modifications in ozone concentrations at the two stations considered in the distance function. Moreover, ozone concentrations are modified similarly at both stations. At Menz agreement cannot be improved significantly without overestimating the ozone concentrations at Eichstaedt. This effect is reflected in the modified diurnal cycles of the ozone concentration for both stations drawn in Fig. 15.

The lowest minimum of the distance function is calculated for the reaction rates. Ozone concentrations at the Menz and Eichstaedt stations based on the modified reaction rates agree quite well with the observations in the assimilation window (Fig. 15). This indicates that uncertainties in the reaction rates may be the cause of the discrepancies in ozone concentration. The sensitivity analysis of the photolysis rates shows that in the area of Menz and south of it high nega-
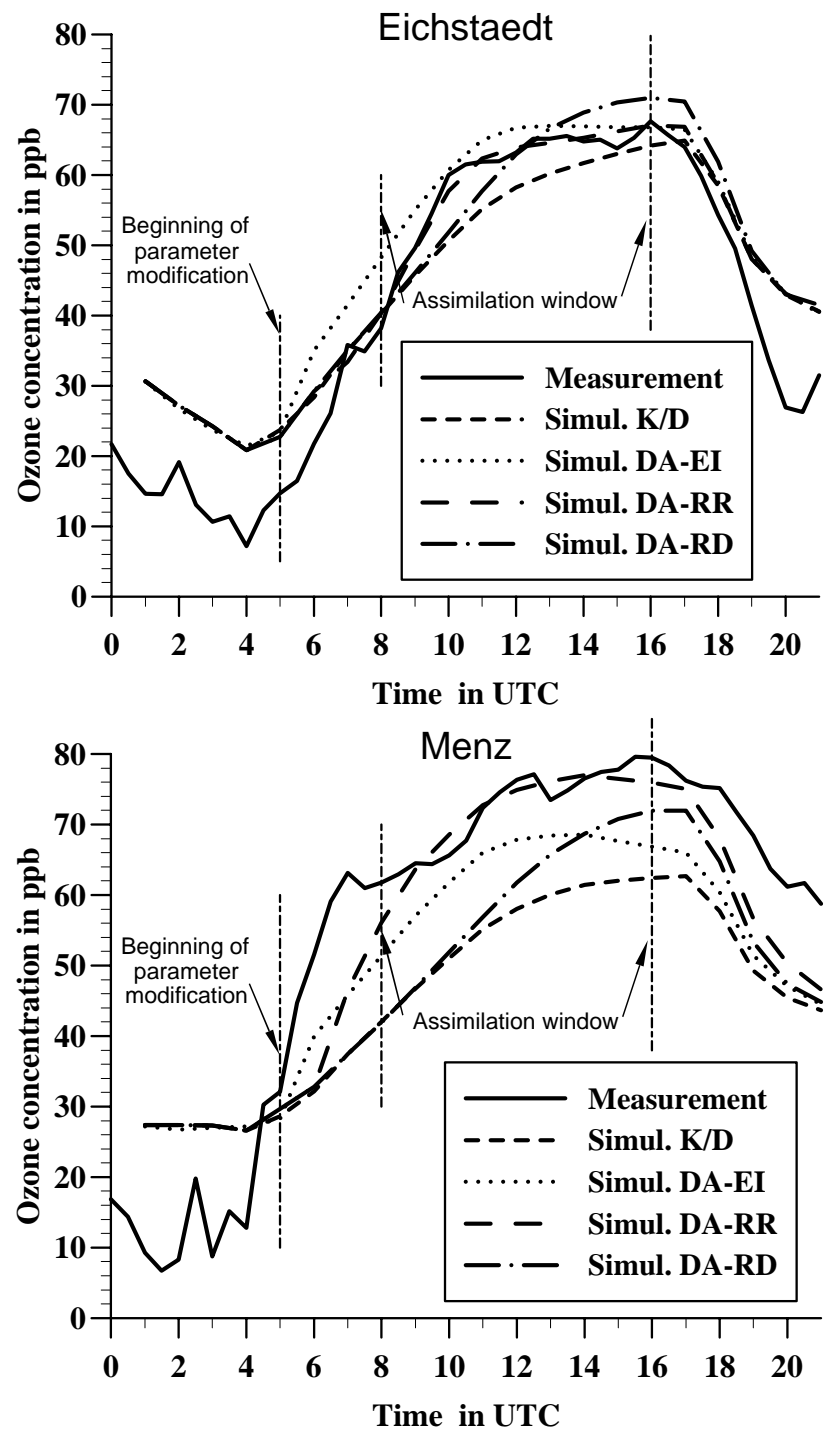

Fig. 15. Diurnal cycle of the ozone concentration at ground level for the stations of Eichstaedt and Menz (K/D: Reference case with $20 \mathrm{~km}$ resolution, DA: Data assimilation, EI: Emissions and Initial concentrations; RR: Photolysis - and other Reaction Rates; RD: Boundary concentrations).

tive sensitivity values are calculated up to a height of about $750 \mathrm{~m}$. After the data assimilation, the $\mathrm{NO}_{2}$ photolysis rate in this volume is increased by the limiting factor of 1.4 . Because the $\mathrm{NO}_{2}$ photolysis rates used in the basic simulation are valid for standard conditions without clouds, such a great increase is not probable over the whole day. Similar results are found for the modified $\mathrm{CH}_{2} \mathrm{O}$ photolysis rate and other relevant reaction rates. This means that the good agreement of the ozone concentrations at the Eichstaedt and Menz stations are probably caused by unrealistic modifications of the photolysis and reaction rates. 
Varying the emissions together with the initial conditions furnishes less satisfactory agreement than modifying the reaction rates does. In the volume around and above Berlin, which is the most sensitive region, the emissions can reach also their maximum possible modifications after the simplified data assimilation. Although these modifications may be more realistic than in the previous case, the observed discrepancies in the ozone concentration can only be partly explained. It seems that errors in only one type of parameter cannot explain the ozone discrepancies at Menz station.

In the late afternoon, after 16:00 UTC (the end of assimilation), the ozone concentrations in the KAMM/DRAIS reference simulation and in all runs with modified parameters converge relatively fast. Especially, the increased ozone concentration at the station Menz after 16:00 UTC is simulated properly neither by the reference run nor by the runs with modified model parameters. This is an indication that additional reasons could still be responsible for the discrepancies between the measured and the calculated ozone concentrations at Menz station. In order to check the results discussed above, corresponding comparisons have been carried out based on the ozone concentrations at the stations Lotharhof and Neuglobsow, which are located $15 \mathrm{~km}$ west-south-west of Menz and $12 \mathrm{~km}$ north-north-west of Eichstädt, respectively. The results for the station Lotharhof confirm those for the station Menz. For Neuglobsow the results are similar to those for the station Eichstädt. But the best agreement is not found for the modified reaction rates. This is an additional indication that the modified reaction rates may not be realistic.

\section{Conclusions}

On 20 July 1998, a day in the BERLIOZ experiment, an ozone plume developed downwind of the city of Berlin. Although the meteorological conditions and ozone concentrations on the upwind side of the city are well simulated by the model, the maximum increase in ozone concentration as observed in the plume is underestimated by $10-15 \mathrm{ppb}$ at distances of $60-80 \mathrm{~km}$ downwind from the city. In this area, the ozone net production rate calculated by the model is lower than that derived from aircraft measurements. A sensitivity analysis was carried out to find the reason for this underestimation. It is based on a distance function defined as the sum of the least squares between the measured and the simulated ozone concentrations at the stations of Eichstaedt and Menz during the period from 08:00 UTC until 16:00 UTC. The emissions, initial conditions and boundary conditions, and the reaction rates are taken as model parameters. The highest sensitivities are listed in Table 2 arranged by absolute values.

Only five parameters show a sensitivity of more than $\pm 100 \mathrm{ppb}^{2}$. The others are a factor of two or more lower. The first five parameters are directly related to the concentration
Table 2. Ranking of sensitivities.

\begin{tabular}{ccc}
\hline Consec. number & Sensitivity $\left(\mathrm{ppb}^{2}\right)$ & Parameter \\
\hline 1 & -188.8 & O3 bound. cond. \\
2 & -171.9 & Photol. rate No. 1 \\
3 & 160.2 & React. rate No. 6 \\
4 & 159.5 & NO emissions \\
5 & -123.4 & O3 init. cond. \\
6 & 60.1 & React. rate No. 24 \\
7 & -39.9 & React. rate No. 9 \\
8 & -35.2 & Photol. rate No. 11 \\
9 & -30.9 & React. rate No. 54 \\
10 & -29.1 & React. rate No. 67 \\
11 & -28.8 & React. rate No. 30 \\
12 & 28.8 & React. rate No. 53 \\
13 & -26.8 & OLT emissions \\
14 & -21.6 & XYL emissions \\
15 & -18.9 & React. rate No. 29 \\
16 & -18.0 & OL2 emissions \\
17 & -16.9 & HC5 emissions \\
18 & -16.4 & HC3 emissions \\
19 & -14.3 & HC8 emissions \\
20 & -10.2 & CO emissions \\
\hline
\end{tabular}

or the production of ozone. It was to be expected that other parameters, such as the hydrocarbon and $\mathrm{CO}$ emissions, also show relevant sensitivities (Table 2). However, their place in the ranking list and their sensitivity values depend on the problem considered.

In addition, simplified 4-D data assimilations were performed. The simulation with the modified reaction rates shows a remarkable reduction of the distance function. But these reaction rates seem to be unrealistic for the whole simulation period. Therefore, the good agreement of the measured and simulated ozone concentrations at Eichstaedt and Menz stations should not be overestimated.

The simulation with the modified emissions and initial conditions also produces a remarkable better agreement between the measured and the simulated ozone concentrations compared to the reference simulation. But the high ozone concentrations in the afternoon are not completely reproduced.

The simulation with boundary conditions modified by data assimilation cannot describe the increase of the ozone concentration in the morning hours.

From all these results it can be concluded that the week agreement between the measured and simulated ozone concentration at Menz station cannot be explained by an error in only one parameter set of the reference run. 
Strictly speaking, the results of this study are of course applicable only to the DRAIS model and the specific episode. Although we could not clearly decide which parameters are responsible for the observed discrepancies, the procedure is also applicable to other models and episodes. Discrepancies between measured and simulated species concentrations are often found and they are not a typical behaviour of the KAMM/DRAIS model system. In other cases the results of such a study may give more evidence than the results of this study. The ranking of sensitivities for other chemistry transport models and other questions in context with ozone concentrations may be different, but the relevant parameters are largely the same, because they mainly determine the ozone chemistry in such type of models. Therefore, it is not necessary to repeat the whole sensitivity calculations. They can be restricted to the relevant ones derived in this study.

\section{Appendix A}

List of RADM2 transported and emitted chemical species

\begin{tabular}{|c|c|c|c|c|}
\hline $\begin{array}{l}\text { Species } \\
\text { number }\end{array}$ & Species name & Chemical formula & $\begin{array}{l}\text { Symbol used } \\
\text { in the model }\end{array}$ & $\begin{array}{l}\text { Number in } \\
\text { Emission inventory }\end{array}$ \\
\hline 1 & Sulfur dioxide & $\mathrm{SO} 2$ & $\mathrm{SO} 2$ & 1 \\
\hline 2 & Sulfuric acid & $\mathrm{H} 2 \mathrm{SO} 4$ & SULF & 2 \\
\hline 3 & Nitrogen dioxide & $\mathrm{NO} 2$ & $\mathrm{NO} 2$ & 3 \\
\hline 4 & Nitric oxide & NO & NO & 4 \\
\hline 5 & Ozone & $\mathrm{O} 3$ & $\mathrm{O} 3$ & \\
\hline 6 & Nitric acid & HNO3 & HNO3 & \\
\hline 7 & Hydrogen peroxide & $\mathrm{H} 2 \mathrm{O} 2$ & $\mathrm{H} 2 \mathrm{O} 2$ & \\
\hline 8 & Acetaldehyde & $\mathrm{R}-\mathrm{CHO}$ & ALD & 5 \\
\hline 9 & Formaldehyde & $\mathrm{CH} 2 \mathrm{O}$ & $\mathrm{HCHO}$ & 6 \\
\hline 10 & Methyl hydrogen peroxide & $\mathrm{CH} 3 \mathrm{OOH}$ & OP1 & \\
\hline 11 & Other organic peroxides & $\mathrm{R}-\mathrm{OOH}$ & OP2 & \\
\hline 12 & Peroxyacetic acid & $\mathrm{CH} 3 \mathrm{COOOH}$ & PAA & \\
\hline 13 & Formic acid & $\mathrm{HCOOH}$ & ORA1 & \\
\hline 14 & Acetic acid & $\mathrm{CH} 3 \mathrm{COOH}$ & ORA2 & 7 \\
\hline 15 & Ammonia & NH3 & NH3 & 8 \\
\hline 16 & Dinitrogen pentoxide & $\mathrm{N} 2 \mathrm{O} 5$ & $\mathrm{~N} 2 \mathrm{O} 5$ & \\
\hline 17 & Nitrogen trioxide & NO3 & NO3 & \\
\hline 18 & Peroxyacetylnitrate & $\mathrm{CH} 3 \mathrm{CO} 3 \mathrm{NO} 2$ & PAN & \\
\hline 19 & $\mathrm{C} 3$ to $\mathrm{C} 5$ alkanes & C3H8-C5H12 & $\mathrm{HC} 3$ & 9 \\
\hline 20 & C6 to $\mathrm{C} 8$ alkanes & C6H14-C8H18 & HC5 & 10 \\
\hline 21 & Other alkanes & $>\mathrm{C} 10 \mathrm{H} 22$ & $\mathrm{HC} 8$ & 11 \\
\hline 22 & Ethane & $\mathrm{C} 2 \mathrm{H} 6$ & ETH & 12 \\
\hline 23 & Carbon monoxide & $\mathrm{CO}$ & $\mathrm{CO}$ & 13 \\
\hline 24 & Ethene & $\mathrm{C} 2 \mathrm{H} 4$ & OL2 & 14 \\
\hline 25 & Terminal alkenes (propene) & e.g. C3H6 & OLT & 15 \\
\hline 26 & Internal alkenes (butene) & e.g. $\mathrm{C} 4 \mathrm{H} 8$ & OLI & 16 \\
\hline 27 & Toluene & $\mathrm{CH} 3 \mathrm{C} 6 \mathrm{H} 5$ & TOL & 17 \\
\hline 28 & Xylene & $(\mathrm{CH} 3) 2 \mathrm{C} 6 \mathrm{H} 4$ & XYL & 18 \\
\hline 29 & Acetyl peroxyl radical & $\mathrm{CH} 3-\mathrm{CO} 3$ & $\mathrm{ACO} 3$ & \\
\hline 30 & other PAN & $\mathrm{CHOCH}=\mathrm{CHCO} 3 \mathrm{NO} 2$ & TPAN & \\
\hline 31 & Nitrous acid & HNO2 & HONO & \\
\hline 32 & Pernitric acid & HNO4 & HNO4 & \\
\hline 33 & Ketones & $\mathrm{CH} 3 \mathrm{COCH} 3, \mathrm{CH} 3 \mathrm{COC} 2 \mathrm{H} 5$ & KET & 19 \\
\hline 34 & Glyoxal & $(\mathrm{CHO}) 2$ & GLY & \\
\hline 35 & Methylglyoxal & $\mathrm{CH} 3 \mathrm{COCHO}$ & MGLY & \\
\hline 36 & Other dicarbonyls & $\mathrm{R}-(\mathrm{CHO}) 2$ & DCB & \\
\hline 37 & Other organic nitrate & R-ONO2 & ONIT & \\
\hline 38 & Cresol & HOC6H4-CH3 & CSL & 20 \\
\hline 39 & Isoprene & $\mathrm{C} 5 \mathrm{H} 8$ & ISO & 21 \\
\hline 40 & Hydroxy radical & $\mathrm{HO}$ & $\mathrm{HO}$ & \\
\hline 41 & Hydroperoxy radical & $\mathrm{HO} 2$ & $\mathrm{HO} 2$ & \\
\hline
\end{tabular}


Edited by: A. Hofzumahaus

\section{References}

Adrian, G. and Fiedler, F.: Simulation of unstationary wind and temperature fields over complex terrain and comparison with observations, Contrib. Atmos. Phys., 64, 27-48, 1991.

Baer, M. and Nester, K.: Parametrization of trace gas dry deposition velocities for a regional mesoscale diffusion model, Ann. Geophys., 10, 912-923, 1992, mboxhttp://www.anngeophys.net/10/912/1992/.

Becker, K. H., Donner, B., and Gäb, S.: BERLIOZ: A field experiment within the German Tropospheric Research Programme, in: Proc. of EUROTRAC Symposium 98, vol. 2, edited by: Borrell, P. M. and Borrell, P., WIT-Press, Southampton, 669-672, 1999.

Chang, J. S., Brost, A., Isaksen, I. S. A., Madronich, S., Middleton, P., Stockwell, W. R., and Walceck, C. J.: A three-dimensional Eulerian acid deposition model: Physical concepts and formulation, J. Geophys. Res., 92, 14 618-14 700, 1987.

Corsmeier, U., Kalthoff, N., Vogel, B., Hammer, M.-U., Fiedler, F., Kottmeier, Ch., Volz-Thomas, A., Konrad, S., Glaser, K., Neininger, B., Lehning, M., Jaeschke, W., Memmesheimer, M., Rappenglück, B., and Jakobi, G.: Ozone and PAN formation inside and outside of the BERLIN plume-Process analysis and numerical process simulation, J. Atmos. Chem., 42, 289-321, 2002.

Degrazia, G. A.: Anwendung von Ähnlichkeitsverfahren auf die turbulente Diffusion in der konvektiven und stabilen Grenzschicht, Dissertation, Fakultät für Physik der Universität Karlsruhe, Institut für Meteorologie und Klimaforschung, 1988.

Dufour, A., Amodel, M., Ancellet, G., and Peuch, V. H.: Observed and modelled "chemical weather" during ESCOMPTE, Atmos. Res., 74, 161-189, 2005.

Ebel, A., Elbern, H., Feldmann, H., Jakobs, H. J., Kessler, C., Memmesheimer, M., Oberreuter, A., and Piekorz, G.: Air pollution studies with the EURAD model system (3): EURADEuropean air pollution dispersion model system, Mitteilungen aus dem Institut für Geophysik und Meteorologie der Universität Köln, Heft 120, p. 172, 1997.

Elbern, H., Schmidt, H., Talagrand, O., and Ebel, A.: 4D-variational data assimilation with an adjoint air quality model for emission analysis, Environ. Modelling \& Software, 15, 539-548, 2000.

Elbern, H. and Schmidt, H.: Ozone episode analysis by fourdimensional variational chemistry data assimilation, J. Geophys. Res., 106(D4), 3569-3590, 2001.

Elbern, H. and Schmidt, H.: The development of a $4 \mathrm{~d}$ variational chemistry data assimilation scheme for initial value and emission rate estimates, in: Proceedings of the 6th GLOREAM Workshop, Aveiro, Portugal, 4-6 September, edited by: Borego, C., Builtjes, P., Miranda, A. I., Santos, P., and Carvalho, A. C., 123-132, 2002.

Elizondo, D., Cappelaere, B., and Faure, Ch.: Automatic versus manual model differentiation to compute sensitivities and solve non-linear inverse problems, Computers \& Geosciences, 28, 309-326, 2002.

Giering, R. and Kaminski, T.: Recipes for adjoint code construction, ACM Transactions on Mathematical Software, 24(4), 437474, 1998

Memmesheimer, M., Ebel, A., and Roemer, F.: Budget calculations for ozone and its precursors: Seasonal and episodic fea- tures based on model simulations, J. Atmos. Chem., 28, 283317, 1997.

Menut, L.: Adjoint modelling for atmospheric pollution process sensitivity at regional scale, J. Geophys. Res., 108(D17), ESQ $51-17,2003$.

Nester, K. and Fiedler, F.: Modeling of the diurnal variation of air pollutants in a mesoscale area, Proceedings of the 9th World Clean Air Congress, Montreal, 5, Paper-No. IU-16C.02, 1992.

Nester, K., Fiedler, F. Panitz, H.-J., and Zhao, T.: Simulation of an episode of the BERLIOZ experiment and comparison with measured data, in: Proceedings 4th GLOREAM Workshop, Cottbus, Germany, 20-22 September, edited by: Schaller, E., Builtjes, P, and Münzenberg, A., 8-16, 2000.

Nester, K. and Panitz, H.-J.: Evaluation of the chemistry transport model system KAMM/DRAIS based on daytime ground level ozone data, Int. J. Environ. Pollut., 22(1/2), 87-107, 2004.

Palacios, M., Kirchner, F., Martilli, A., Clappier, A., Martin, F., and Rodrigues, M. E.: Summer ozone episodes in the Greater Madrid Area. Analyzing the ozone response to abatement strategies by modelling, Atmos. Environ., 36, 5323-5333, 2002.

Panitz, H.-J., Nester, K., and Fiedler, F.: Determination of mass balances of chemically reactive air pollutants over BadenWürttemberg (F.R.G.) - Study for the regions around the cities of Stuttgart and Freudenstadt, in: Air Pollution V, edited by: Power, H., Tirabassi, T., Brebbia, C. A., Computational Mechanics Publications, Southampton, Boston, 413-422, 1997.

Panitz, H.-J. and Nester, K.: Mass budget simulations of ozone in the city plume of Berlin for an episode of the BERLIOZ experiment, Companion CD-ROM of: Transport and Chemical Transformation in the Troposphere, edited by: Midgley, P. and Reuther, M., Proceedings of the EUROTRAC Symposium 2002, Garmisch-Partenkirchen, Germany, 11-15 March; see also http:// www-fzk.imk.uni-karlsruhe.de/fi/fzk/imk/seite_1513.php, 2002.

Peleg, M., Luria, M., Sharf, G., Vanger, A., Kallos, G., Kotroni, V., Lagouvardos, K., and Varinou, M.: Observational evidence of an ozone episode over the Greater Athens Area, Atmos. Environ., 31, 3969-3983, 1997.

Plaza, J., Pujadas, M., and Artinano, B.: Formation and transport of the Madrid ozone plume, J. Air Waste Manage. Assoc., 47, 766-774, 1997.

Prevot, A. S. H., Staehlin, L., Kok, G. L., Schillawski, R. D., Neininger, B., Staffelbach, T., Neftel, A., Wernli, H., and Dommen, J.: The Milan photooxidant plume, J. Geophys. Res., 102, 23 375-23 388, 1997.

Pudykiewicz, J. A.: Application of adjoint tracer transport equations for evaluating source parameters, Atmos. Environ., 32(17), 3039-3050, 1998.

Rostaing, N., Dalmas, S., and Galligo, A.: Automatic differentiation in Odyssée, Tellus, 45A, 558-568, 1993.

Schädler, G., Kalthoff, N., and Fiedler, F.: Validation of a model for heat, mass and momentum exchange over vegetated surfaces using LOTREX-10E/HIBE88 data, Contrib. Atmos. Phys., 63, 85-100, 1990.

Schmidt, H. and Martin, D.: Adjoint sensitivity of episodic ozone in the Paris area to emissions on the continental scale, J. Geophys. Res., 108(D17), ESQ 4 1-16, 2003.

Slemr, F., Baumbach, G., Blank, P., Corsmeier, U., Fiedler, F., Friedrich, R., Habram, M., Kalthoff, N., Klemp, D., Kühlwein, J., Mannschreck, K., Möllmann-Coers, M., Nester, K., Panitz, 
H.-J., Rabl, P., Slemr, J., Vogt, U., and Wickert, B.: Evaluation of modelled spatially and temporally highly resolved emission inventories of photosmog precursors for the city of Augsburg: the experiment EVA and its major results, J. Atmos. Chem., 42, 207-233, 2002.

Stockwell, W. R., Middelton, P., and Chang, J. S.: The second generation Regional Acid Deposition Model, chemical mechanism for regional air quality modeling, J. Geophys. Res., 95(D10), 16343-16367, 1990.

Thuburn, J. and Haine, T. W. N.: Adjoints of nonoscillatory advection schemes, J. Comput. Phys., 171, 616-631, 2001.

Talagrand, O. and Courtier, P.: Variational assimilation of meteorological observations with the adjoint vorticity equation. I: Theory, Quart. J. Roy. Meteorol. Soc., 113, 1311-1328, 1987.

Ustinov, E. A.: Adjoint sensitivity analysis of atmospheric dynamics: Application to the case of multiple observables, J. Atmos. Sci., 58(21), 3340-3348, 2001.
Vautard, R., Beekmann, M., and Menut, L.: Applications of adjoint modelling in atmospheric chemistry: sensitivity and inverse modelling, Environ. Modelling \& Software, 25, 703-709, 2000.

Vautard, R., Menut, L., Beekmann, M., Chazette, P., Flamant, P. H., Gombert, D., Kley, D., Lefebvre, M. P., Marti, D., Megie, G., Perros, P., and Toupance, G.: A synthesis of air pollution over the Paris region (ESQUIF) field campaign, J. Geophys. Res.-Atmos., 108(D17, 8558, doi:10.1029/2003JD003380, 2003.

Vogel, B., Fiedler, F., and Vogel, H.: Influence of topography and biogenic volatile organic compounds emission in the state of Baden-Württemberg on ozone concentrations during episodes of high air temperatures, J. Geophys. Res., 100, 22 907-22 928, 1995.

Wotawa, G., Stohl, A., and Neininger, B.: The urban plume of Vienna: Comparison between aircraft measurements and photochemical model results, Atmos. Environ., 32, 2479-2489, 1998. 